\title{
Atherogenic Risk Assessment among Persons Living in Rural Uganda
}

\author{
Clara Wekesa, ${ }^{1}$ Gershim Asiki, ${ }^{1}$ Ivan Kasamba, ${ }^{1}$ Laban Waswa, ${ }^{1}$ Steven J. Reynolds, ${ }^{2,3}$ \\ Rebecca N. Nsubuga, ${ }^{1}$ Rob Newton, ${ }^{1}$ and Anatoli Kamali ${ }^{1}$ \\ ${ }^{1}$ Medical Research Council/Uganda Virus Research Institute Uganda Research Unit on AIDS, Entebbe, Uganda \\ ${ }^{2}$ Division of Intramural Research, National Institute of Allergy and Infectious Diseases, National Institutes of Health, \\ Bethesda, MD 20892, USA \\ ${ }^{3}$ Johns Hopkins School of Medicine, Baltimore, MD 21205, USA
}

Correspondence should be addressed to Clara Wekesa; clara.wekesa@gmail.com

Received 28 April 2016; Revised 27 May 2016; Accepted 29 May 2016

Academic Editor: Marcel Tanner

Copyright (C) 2016 Clara Wekesa et al. This is an open access article distributed under the Creative Commons Attribution License, which permits unrestricted use, distribution, and reproduction in any medium, provided the original work is properly cited.

\begin{abstract}
Background. Hypertension and dyslipidemia are independent risk factors for coronary heart disease and commonly coexist. Cardiovascular risk can be reliably predicted using lipid ratios such as the atherogenic index, a useful prognostic parameter for guiding timely interventions. Objective. We assessed the cardiovascular risk profile based on the atherogenic index of residents within a rural Ugandan cohort. Methods. In 2011, a population based survey was conducted among 7507 participants. Sociodemographic characteristics, physical measurements (blood pressure, weight, height, and waist and hip circumference), and blood sampling for nonfasting lipid profile were collected for each participant. Atherogenic risk profile, defined as logarithm base ten of (triglyceride divided by high density lipoprotein cholesterol), was categorised as low risk $(<0.1)$, intermediate risk $(0.1-0.24)$, and high risk $(>0.24)$. Results. Fifty-five percent of participants were female and the mean age was 49.9 years $(S D \pm 20.2)$. Forty-two percent of participants had high and intermediate atherogenic risk. Persons with hypertension, untreated HIV infection, abnormal glycaemia, and obesity and living in less urbanised villages were more at risk. Conclusion. A significant proportion of persons in this rural population are at risk of atherosclerosis. Key identified populations at risk should be considered for future intervention against cardiovascular related morbidity and mortality. The study however used parameters from unfasted samples that may have a bearing on observed results.
\end{abstract}

\section{Background}

Globally, cardiovascular disease (CVD) is the leading cause of death with up to $80 \%$ occurring in low and middle income countries (LMICs) [1]. Premature death due to CVD is rapidly growing in Sub-Saharan Africa (SSA) [2]. Hypertension and dyslipidemia are thought to be the major risk factors for CVD [3]. A systematic review on hypertension in SSA yielded 17 studies conducted between 1998 and 2008 in 11 countries and found an overall prevalence of $16.2 \%$, with small variation between urban and rural communities [4]. In Uganda, the prevalence of hypertension ranges from $14.6 \%$ in the rural areas [5] to $27.2 \%$ in the periurban area [6]. In Western populations, dyslipidemia among patients with hypertension is a common finding. The prevalence of dyslipidemia coexisting with hypertension has been estimated at $15-24 \%$ [3, 7]. Over $40 \%$ of all newly diagnosed hypertensive patients have at least one lipid abnormality [8]. There is dearth of data on the burden of dyslipidemia among patients with hypertension in SSA.

Hypertension and dyslipidemia are both independent modifiable risk factors for CVD. However, some studies suggest that dyslipidemia may play a role in the development of hypertension via endothelial damage [9]. The risk for CVD is higher in the presence of both hypertension and dyslipidemia than by the individual disease entities [10]. In high income countries, strategies targeting the reduction of serum cholesterol levels provide the single most important benefit against CVD resulting from coronary heart disease (CHD) when evaluated in a cohort setting [11]. A review on 
a number of cohort studies and randomised clinical trials found that a $10 \%$ decrease in cholesterol reduced the risk of $\mathrm{CHD}$ by $50 \%$ at the age of 40 and this benefit reduces to $20 \%$ by the age of 70 [12]. In contrast, blood pressure control provides only a $20 \%$ risk reduction of mortality due to $\mathrm{CHD}$ in high income settings.

Current medical practice encourages risk stratification for all persons at risk of CHD including those with hypertension. This is advantageous for timely intervention in preventing $\mathrm{CHD}$ and its sequelae. Cardiovascular risk assessment based solely on serum low density lipoprotein cholesterol (LDL-C) has been found to be inadequate $[13,14]$ and even in persons on statin therapy with normal or near normal LDL-C serum levels, there remains risk for future cardiovascular events. Hypertriglyceridemia has been identified as an independent cardiovascular risk factor $[15,16]$. Hypertriglyceridemia is a proxy for atherogenic dyslipidemia (elevated TG (triglyceride) and low high density lipoprotein cholesterol) $[16,17]$, a component of the metabolic syndrome and a known risk factor for CHD. Despite interaction with other lipids that might increase atherogenic risk and in-subject variation, elevated TG has been shown to be a good predictor of CHD in consideration of the high density lipoprotein cholesterol (HDL-C) levels [17] and is used in clinical practice to predict atherosclerosis $[17,18]$. The lipid ratio log [TG/HDL-C] (atherogenic index) provides an alternative simple option for risk stratification. The use of this ratio is to reflect the balance between risk and protective lipoprotein forces [15] as well as acting as a correlate with LDL-C particle size [19], LDL-phenotype B, and small HDL-C particles [16]. This ratio has also been evaluated as a prognostic tool in predicting CHD [16] and its predictive value far outweighs that of absolute lipid parameters $[20,21]$ as well as the TC (total cholesterol)/HDL ratio [21] given its strong correlation with lipoprotein particle size.

Uganda bears a significant burden of hypertension [22] and like other SSA countries is not presently equipped with the necessary resources, expertise, and technology to manage the CVD sequelae. A recent study done within a rural population reflected the dominant dyslipidemic pattern to be that of low serum HDL-C levels and a good proportion with hypertriglyceridemia [23]. Whereas there are well-recognised recommendations on the use of serum LDL-C and TC for cardiovascular risk assessment, there is limited progress in addressing concerns with low serum HDL-C which may lead to underestimation of CHD risk [24]. The atherogenic index provides a simple and reliable method for point of care risk assessment that can be done by nonspecialists even within hard-to-reach areas. The aim of this study was to assess the atherogenic risk profile using the atherogenic index among people living in rural Uganda.

\section{Methods}

2.1. Design and Setting. A population based survey was conducted in 2011 among 7507 individuals aged 13 years and above living in an established rural cohort in southwestern Uganda, the General Population Cohort (GPC) consisting of 25 villages. This cohort has been in existence for the last
25 years and was initially established for the purpose of investigating HIV trends in rural Uganda. Research activities have since been broadened to include noncommunicable diseases, assessing burden and risk factors [25].

\subsection{Study Procedures}

2.2.1. Questionnaire. Sociodemographic information was collected for each participant and entered into an electronic questionnaire. This information included age, sex, and occupation, level of education, marital status, smoking history, and use of alcohol. The level of urbanicity was determined and presented as described elsewhere [26].

2.2.2. Physical Measurements. Blood pressure measurement, height, weight, and hip and waist circumferences were measured as described by Riha et al. 2014 [26]. Participants found to have systolic blood pressure $\geq 140 \mathrm{mmHg}$ and/or diastolic pressure $\geq 90 \mathrm{mmHg}$ were referred to as having hypertension. Participant categorisation using body mass index (BMI) was as follows: BMI $\leq 18.5$, "underweight," BMI 18.5-24.9, "normal weight," BMI 25-29.9, "overweight," and BMI $\geq 30$, "obese". Categorisation by waist-hip ratio (WHR) was as follows: abnormal in male if $>0.95$ and abnormal in females if $>0.8$.

2.2.3. Laboratory Measurements. Participants underwent phlebotomy for purposes of a nonfasting lipid profile (TC, TG, HDL-C, and low density lipoprotein cholesterol (LDLC)), HIV serology, and glycated haemoglobin (HbAlc). All blood samples were transported on the same day to a central laboratory for sample processing and testing. Lipid profile analysis was done using the enzymatic colorimetric assay by the Cobas Integra 400 Plus. Cut-off values for the different lipid parameters representative of dyslipidemia were as follows: TC $>5.2 \mathrm{mmol} / \mathrm{L}, \mathrm{TG}>2.3 \mathrm{mmol} / \mathrm{L}$, LDL$\mathrm{C}>3.4 \mathrm{mmol} / \mathrm{L}$, and HDL-C $<1.04 \mathrm{mmol} / \mathrm{L}$, male, and $<1.3 \mathrm{mmol} / \mathrm{L}$, female. Participants with $\mathrm{HbAlc} \geq 6.5 \%$ were termed as diabetic, HbAlc 6-6.49\% were termed as high risk for diabetes, and $\mathrm{HbAlc}<6 \%$ were termed as low risk for diabetes [27]. HIV testing was done in accordance with the Ministry of Health guidelines [28].

2.3. Data Analysis. To assess the atherogenic risk we used the atherogenic index defined as $\log$ (triglycerides/HDL-C). The risk was categorised into low $(<0.1)$, intermediate $(0.1-0.24)$, and high $(>0.24)$ [21].

The sample was described using proportions by sex. Age and systolic and diastolic blood pressure were summarized with means and corresponding standard deviations (SD). Atherogenic risk was determined using proportions in each category and the chi-squared test was used to compare proportions. We used the ordered logistic regression model to evaluate the effect of demographic characteristics, blood pressure, lipid profiles, and HIV status on atherogenic risk and the results were presented by sex. To avoid residual confounding and loss of power, continuous lipid measures were modelled as continuous rather than categorised. 
The continuous variables were included into the model as centered and assessed for nonlinearity by fitting a firstorder fractional polynomial to the data. The proportional odds assumption in using the ordered logistic regression was tested. Analysis was done using STATA 13 (Stata Corp, College Station, TX).

2.4. Ethical Consideration. The study was conducted in accordance with the principles of the Declaration of Helsinki and was approved by the Uganda Virus Research Institute Research Ethics Committee (UVRI REC) in Entebbe, Uganda, and by the Uganda National Council of Science and Technology (UNSCT). Written informed consent was obtained from all study participants. For participants below the age of 18 years, parental consent and formal assent to participate in the study were obtained as per the Ugandan National Guidelines for Research Involving Humans as Research Participants [29]. Participants with hypertension and raised serum lipids were referred to a care clinic for further management and received standard of care (health education on risk factor prevention and/or control and drug therapy with statins).

\section{Results}

3.1. Baseline Characteristics. The study enrolled 7507 participants, the majority were females $(55 \%)$, and the mean age was 49.9 years $(S D \pm 20.2)$. There were equal distributions of participants across the different levels of urbanicity, most of the participants were under the age of 30 , and the use of alcohol and tobacco was more common among the male participants (Table 1).

From the physical and laboratory measurements we found more female participants to be overweight and obese and have an abnormal WHR. Approximately $18 \%$ of participants were identified as having hypertension and only $2 \%$ had controlled hypertension on treatment. The most common form of dyslipidemia was low serum HDL-C levels (Table 1).

3.2. Atherogenic Risk. The proportion of participants with intermediate and high atherogenic risk was $17 \%$ and $25 \%$, respectively, with the greater proportion at high risk being male participants (Figure 1).

3.3. Risk Factors for High Atherogenic Risk. Participants with hypertension (particularly those with suboptimal control on treatment), residents from less urbanised villages, HIVinfected participants not on antiretroviral therapy (ART), overweight and obese participants, and participants with abnormal HbAlc had significantly higher odds of having high atherogenic risk (Table 2).

Being female, 30 years of age and above, having attained higher level of education, current consumption of alcohol, and being on ART were significantly associated with lower odds of having high atherogenic risk. Abnormal total cholesterol serum levels and history of smoking had no association with atherogenic risk.

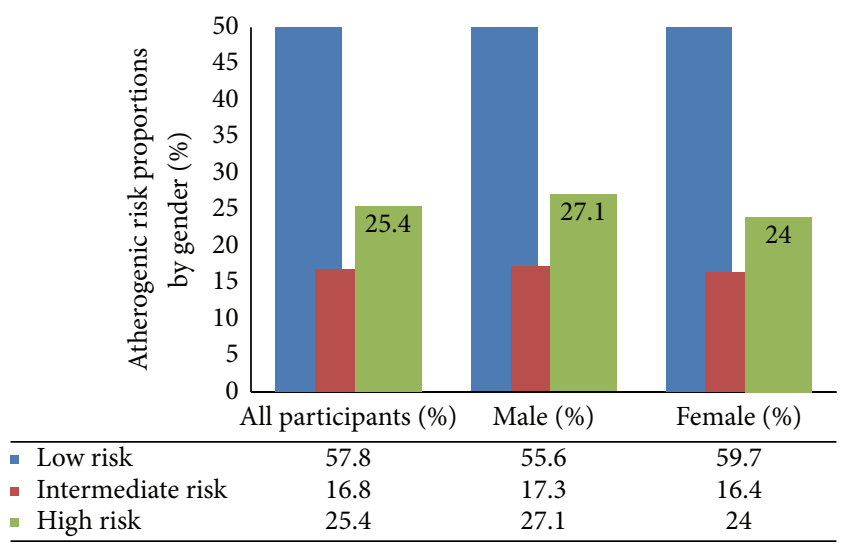

FIGURE 1: Atherogenic risk profile among study participants stratified by gender.

\section{Discussion}

With increasing globalisation, varying degrees of urbanisation exist even within rural areas [26]. Urbanisation influences environmental and individual factors that may have impact on cardiovascular risk. In this study we assessed the risk for atherosclerosis using the atherogenic index in a rural Ugandan cohort. The atherogenic index in comparison to absolute lipid parameters and to TC/HDL-C ratio provides more accurate estimates of cardiovascular risk [30] and is more likely to be a better screening tool. Our study is one of the few studies in the region that provides insight into the use of the atherogenic index and having a cohort already in establishment provides the unique opportunity to conduct pilot studies that generate hypotheses to guide future research in this field. This study also assesses the use of the atherogenic index in a widely distributed rural population and is not only restricted to most at-risk populations. The atherogenic index requires minimal expertise and can be widely implemented as a screen method for cardiovascular disease even within remote locations.

A significant proportion of participants were at risk of atherosclerosis. A population based survey done in Iran and using the atherogenic index found a similar high estimate of atherogenic risk [31]. The INTERHEART study, an observational study involving 52 countries spread across all continents, found that persons with history of myocardial infarction had three times the odds of having a raised ApoB/ApoA1 ratio (surrogate for atherogenic dyslipidemia) compared to persons without history of myocardial infarction [32]. An observational study done in Brazil found that persons with coronary disease had two times the odds of having an abnormal TG/HDL-C ratio [33]. In our study participants with hypertension had higher odds of risk for atherosclerosis. We found that $27 \%$ of participants with hypertension had a high atherogenic risk, a higher estimate compared to a Nigerian study that found a lower proportion of patients with hypertension at risk for CHD using LDL-C/HDL-C ratios for risk stratification [30]. We attributed this difference in proportions to the atherogenic index being a correlate to 
TABLE 1: Sociodemographic, clinical, physical, and biochemical characteristics of cohort by gender.

\begin{tabular}{|c|c|c|c|}
\hline & \multirow{2}{*}{$\begin{array}{c}\text { All participants } \\
n(\%)\end{array}$} & \multicolumn{2}{|c|}{ Sex } \\
\hline & & Male, $n(\%)$ & Female, $n(\%)$ \\
\hline All & 7507 & 3378 & 4129 \\
\hline \multicolumn{4}{|l|}{ Demographic characteristics } \\
\hline \multicolumn{4}{|l|}{ Age, in years } \\
\hline $13-29$ & $3679(49.0)$ & $1804(53.4)$ & $1875(45.4)$ \\
\hline $30-59$ & $2978(39.7)$ & $1226(36.3)$ & $1752(42.4)$ \\
\hline $60+$ & $850(11.3)$ & $348(10.3)$ & $502(12.2)$ \\
\hline \multicolumn{4}{|l|}{ Urbanicity score* } \\
\hline Quartile 1 (least urban) & $1978(26.4)$ & $884(26.2)$ & $1094(26.5)$ \\
\hline Quartile 2 & $1893(25.2)$ & $848(25.1)$ & $1045(25.3)$ \\
\hline Quartile 3 & $1946(25.9)$ & $888(26.3)$ & $1058(25.6)$ \\
\hline Quartile 4 (most urban) & $1690(22.5)$ & $758(22.4)$ & $932(22.6)$ \\
\hline \multicolumn{4}{|l|}{ Highest education level } \\
\hline None/up to P4 & $2112(28.1)$ & $876(25.9)$ & $1236(29.9)$ \\
\hline P5-P7 & $3365(44.8)$ & $1579(46.7)$ & $1786(43.3)$ \\
\hline Secondary+ & $2030(27.0)$ & $923(27.3)$ & $1107(26.8)$ \\
\hline \multicolumn{4}{|l|}{ Occupation } \\
\hline Subsistence crop & $2975(39.6)$ & $1102(32.6)$ & $1873(45.4)$ \\
\hline Cash crop cultivator & $934(12.4)$ & $491(14.5)$ & $443(10.7)$ \\
\hline Noncrop & $1043(13.9)$ & $625(18.5)$ & $418(10.1)$ \\
\hline Unemployed/full-time education & $2555(34.0)$ & $1160(34.3)$ & $1395(33.8)$ \\
\hline \multicolumn{4}{|l|}{ Marital status ${ }^{* *}$} \\
\hline Not married/divorced & $3861(51.5)$ & $1842(54.6)$ & $2019(48.9)$ \\
\hline Married/living & $3638(48.5)$ & $1532(45.4)$ & $2106(51.1)$ \\
\hline \multicolumn{4}{|l|}{ Lifestyle characteristics } \\
\hline \multicolumn{4}{|l|}{ Smoking } \\
\hline Never smoked & $6747(89.9)$ & $2707(80.1)$ & $4040(97.8)$ \\
\hline Ever smoked daily & $760(10.1)$ & $671(19.9)$ & $89(2.2)$ \\
\hline \multicolumn{4}{|l|}{ Alcohol consumption } \\
\hline Never drinker & $4844(64.5)$ & $2032(60.2)$ & $2812(68.1)$ \\
\hline Ex-drinker & $583(7.8)$ & $235(7.0)$ & $348(8.4)$ \\
\hline Current drinker & $2080(27.7)$ & $1111(32.9)$ & $969(23.5)$ \\
\hline \multicolumn{4}{|l|}{ Biophysical characteristics } \\
\hline \multicolumn{4}{|l|}{ BMI group } \\
\hline Underweight $(<18.5)$ & $1701(22.7)$ & $1022(30.3)$ & $679(16.4)$ \\
\hline Normal (18.5-24.9) & $4878(65.0)$ & $2179(64.5)$ & $2699(65.4)$ \\
\hline Overweight $(\geq 25)$ & $730(9.7)$ & $156(4.6)$ & $574(13.9)$ \\
\hline Obese & $198(2.6)$ & $21(0.6)$ & $177(4.3)$ \\
\hline \multicolumn{4}{|l|}{ Waist-hip ratio (WHR) } \\
\hline Normal $(\leq 0.95-m, \leq 0.80-f)$ & $4440(59.1)$ & $3257(96.4)$ & $1183(28.7)$ \\
\hline Abnormal $(>0.95-\mathrm{m},>0.80-\mathrm{f})$ & $3067(40.9)$ & $121(3.6)$ & $2946(71.3)$ \\
\hline \multicolumn{4}{|l|}{ Biochemical characteristics } \\
\hline \multicolumn{4}{|l|}{ Total cholesterol } \\
\hline Desirable $(\leq 5.2 \mathrm{mmol} / \mathrm{L})$ & $7084(94.4)$ & $3270(96.8)$ & $3814(92.4)$ \\
\hline $\operatorname{High}(>5.2 \mathrm{mmol} / \mathrm{L})$ & $423(5.6)$ & $108(3.2)$ & $315(7.6)$ \\
\hline \multicolumn{4}{|l|}{ Triglycerides } \\
\hline Desirable $(\leq 2.3 \mathrm{mmol} / \mathrm{L})$ & $7190(95.8)$ & $3261(96.5)$ & $3929(95.2)$ \\
\hline High $(>2.3 \mathrm{mmol} / \mathrm{L})$ & $317(4.2)$ & $117(3.5)$ & $200(4.8)$ \\
\hline \multicolumn{4}{|l|}{$L D L-C$} \\
\hline Desirable $(\leq 3.4 \mathrm{mmol} / \mathrm{L})$ & $7134(95.0)$ & $3286(97.3)$ & $3848(93.2)$ \\
\hline $\operatorname{High}(>3.4 \mathrm{mmol} / \mathrm{L})$ & $373(5.0)$ & $92(2.7)$ & $281(6.8)$ \\
\hline$H D L-C$ & & & \\
\hline Desirable ( $\geq 1.04-\mathrm{m}, 1.3-\mathrm{f})$ & $1940(25.8)$ & $1127(33.4)$ & $813(19.7)$ \\
\hline Undesirable (<1.04-m, 1.3-f), low & $5567(74.2)$ & $2251(66.6)$ & $3316(80.3)$ \\
\hline $\mathrm{HbAl-C}$ & & & \\
\hline Normal $(\leq 6 \%)$ & 7469 (99.7) & $3359(99.8)$ & $4110(99.7)$ \\
\hline Raised ( $\geq 6.5 \%)$ & $19(0.3)$ & $7(0.2)$ & $12(0.3)$ \\
\hline
\end{tabular}


TABle 1: Continued.

\begin{tabular}{|c|c|c|c|}
\hline & \multirow{2}{*}{$\begin{array}{c}\text { All participants } \\
n(\%)\end{array}$} & \multicolumn{2}{|c|}{ Sex } \\
\hline & & Male, $n(\%)$ & Female, $n(\%)$ \\
\hline \multicolumn{4}{|l|}{ Clinical characteristics } \\
\hline \multicolumn{4}{|l|}{ Hypertension status } \\
\hline Normal BP & $6163(82.1)$ & 2799 (82.9) & $3364(81.5)$ \\
\hline Normal BP on treatment & $173(2.3)$ & $56(1.7)$ & $117(2.8)$ \\
\hline Raised on treatment & $119(1.6)$ & $31(0.9)$ & $88(2.1)$ \\
\hline Raised BP, not on treatment & $1050(14.0)$ & $492(14.6)$ & $558(13.5)$ \\
\hline \multicolumn{4}{|l|}{ HIV/ART status } \\
\hline Negative & $6821(92.0)$ & $3103(93.5)$ & $3718(90.7)$ \\
\hline Positive, on ART & $201(2.7)$ & $63(1.9)$ & $138(3.4)$ \\
\hline Positive, not on ART & $396(5.3)$ & $152(4.6)$ & $244(6.0)$ \\
\hline \multicolumn{4}{|l|}{ Atherogenic risk } \\
\hline Low $(<0.1)$ & $4341(57.8)$ & $1878(55.6)$ & $2463(59.7)$ \\
\hline Intermediate (0.1-0.24) & $1259(16.8)$ & $583(17.3)$ & $676(16.4)$ \\
\hline High $(>0.24)$ & $1907(25.4)$ & $917(27.1)$ & $990(24.0)$ \\
\hline
\end{tabular}

${ }^{*}$ Riha et al. 2014 [26].

${ }^{* *} 8$ missing pieces of information.

lipoprotein size [21] which may predict risk better. Participants on treatment, but with uncontrolled hypertension, were more likely to be at risk of atherosclerosis compared to those not on treatment and those with controlled hypertension. Literature shows that blood pressure control gives minimal reduction of cardiovascular risk especially among those older than 40 years [12] and in our study we found the mean age to be 49 years. This could explain why even among participants on treatment and controlled hypertension atherogenic risk was still high. Participants that were HIV infected and ART naive were more likely to have a high atherogenic risk, a finding similar to other studies done, possibly owing to their high inflammatory state [34]. The use of ART was found to be protective as ART is thought to reduce inflammatory markers and provide cardioprotection [35]. However, other studies have found the use of protease inhibitors (PI) to increase the serum levels of atherogenic lipoproteins [34]. In this population first-line therapy was non-PI based and could further explain our findings. We also observed that a high atherogenic index was less prevalent in participants aged 60 years and above and yet it is more likely that individuals in this age category are more at risk of cardiovascular events. The HIV prevalence in this cohort is higher in the younger age group and we thought this may be the main driver for the increased risk in this age group.

Abnormal HbAlc as a screen for diabetes was also found to be associated with high atherogenic risk. Diabetes affects the integrity of the vasculature and is also associated with other conditions that predispose to CHD, such as hypertension and dyslipidemia that may explain the increased risk. Previous epidemiological studies have shown cholesterol to predict risk of CHD and LDL-C to be associated with future risk [36]; however, we did not find any association between high serum cholesterol levels and atherogenic risk in this rural population. Similar to the Framingham study [36] and the INTERHEART study [32] we demonstrated that obesity and abdominal obesity were associated with increased risk of CHD in this study population. Our study showed that participants from less urbanised villages were more likely to be at high risk for $\mathrm{CHD}$. However previous studies done within this same population showed that persons in less urbanised villages were more likely to indulge in physical activity and eat fruits and vegetables [26], factors thought to reduce risk for CHD. It may be possible that a different set of risk factors, yet to be explored, is responsible for the risk of CHD in this population.

Our study was limited in that we did not derive lipid parameters from fasted samples which may impact on risk estimation if there should be any variation with parameters derived after fasting. We also did not ascertain differences among the subcategories of participants with hypertension that may have accounted for differences in risk profile. The design of the study did not allow making inferences as to casualty. However this study provides insight into estimated cardiovascular risk in a widely distributed rural population taking into account environmental, infectious, and noninfectious risk factors and provides a platform for further research into possible causes of high atherogenic risk whose findings may give information on preventive strategies.

\section{Conclusion}

A significant proportion of persons in this rural Ugandan population are at risk of atherosclerosis. Persons with hypertension, untreated HIV infection, abnormal glycaemia, and obesity appear to be more at risk and may be considered as target groups for intervention programs. Follow-up studies are needed to further assess other risk factors including the role of genetics in cardiovascular risk in this population. 
TABLE 2: Factors associated with high atherogenic risk.

\begin{tabular}{|c|c|c|c|c|c|}
\hline Covariates & $\begin{array}{c}\text { High atherogenic risk } \\
n(\%)\end{array}$ & Crude $\mathrm{OR}^{\phi}$ & & $\begin{array}{c}\text { Adjusted } \mathrm{OR}^{\phi} \\
\text { b/ci95 }\end{array}$ & Overall $p$ value \\
\hline \multicolumn{6}{|l|}{ Hypertension status } \\
\hline Normal BP $(\leq 140 / 90 \mathrm{mmHg})(n=6163)$ & $1538(25.0)$ & 1 & 0.022 & 1 & 0.007 \\
\hline Normal BP on treatment $(n=173)$ & $53(30.6)$ & $1.34(1.01-1.78)$ & & $1.32(0.98-1.79)$ & \\
\hline Raised BP $(\geq 140 / 90 \mathrm{mmHg})$ on treatment $(n=119)$ & $36(30.3)$ & $1.51(1.08-2.11)$ & & $1.53(1.07-2.18)$ & \\
\hline Raised BP not on treatment $(n=1050)$ & $280(26.7)$ & $1.04(0.91-1.18)$ & & $1.17(1.00-1.37)$ & \\
\hline \multicolumn{6}{|l|}{ Sex } \\
\hline Male $(n=3378)$ & $917(27.1)$ & 1 & $<0.001$ & 1 & $<0.001$ \\
\hline Female $(n=4129)$ & $990(24.0)$ & $0.85(0.77-0.93)$ & & $0.57(0.50-0.66)$ & \\
\hline \multicolumn{6}{|l|}{ Age, in years } \\
\hline $13-29(n=3679)$ & $980(26.6)$ & 1 & 0.001 & 1 & $<0.001$ \\
\hline $30-59(n=2978)$ & $727(24.4)$ & $0.88(0.80-0.97)$ & & $0.84(0.75-0.94)$ & \\
\hline $60+(n=850)$ & $200(23.5)$ & $0.84(0.71-1.00)$ & & $0.71(0.58-0.87)$ & \\
\hline \multicolumn{6}{|l|}{ Urbanicity score } \\
\hline Quartile 1 (least urban) $(n=1978)$ & $488(24.7)$ & 1 & $<0.001$ & 1 & 0.018 \\
\hline Quartile $2(n=1893)$ & $535(28.3)$ & $1.15(1.02-1.30)$ & & $1.16(1.02-1.31)$ & \\
\hline Quartile $3(n=1946)$ & $473(24.3)$ & $0.94(0.83-1.07)$ & & $0.96(0.85-1.09)$ & \\
\hline Quartile 4 (very urban) $(n=1690)$ & $411(24.3)$ & $0.95(0.83-1.10)$ & & $0.98(0.86-1.12)$ & \\
\hline \multicolumn{6}{|l|}{ Highest education level } \\
\hline None/up to p4 $(n=2112)$ & $596(28.2)$ & 1 & $<0.001$ & 1 & $<0.001$ \\
\hline P5-P7 $(n=3365)$ & $880(26.2)$ & $0.85(0.77-0.95)$ & & $0.81(0.73-0.91)$ & \\
\hline Secondary+ $(n=2030)$ & $431(21.2)$ & $0.66(0.58-0.76)$ & & $0.64(0.55-0.74)$ & \\
\hline \multicolumn{6}{|l|}{ Cigarette consumption } \\
\hline Never smokers $(n=6747)$ & $1718(25.5)$ & 1 & 0.992 & 1 & 0.471 \\
\hline Ever smokers $(n=760)$ & $189(24.9)$ & $1.00(0.86-1.16)$ & & $0.94(0.79-1.11)$ & \\
\hline \multicolumn{6}{|l|}{ Alcohol consumption } \\
\hline Never drinkers $(n=4844)$ & $1276(26.3)$ & 1 & $<0.001$ & 1 & $<0.001$ \\
\hline Ex-drinkers $(n=583)$ & $155(26.6)$ & $1.06(0.90-1.25)$ & & $1.00(0.84-1.20)$ & \\
\hline Current drinkers $(n=2080)$ & $476(22.9)$ & $0.81(0.73-0.89)$ & & $0.78(0.69-0.88)$ & \\
\hline \multicolumn{6}{|l|}{ HIV/ART status } \\
\hline Negative $(n=6821)$ & $1711(25.1)$ & 1 & $<0.001$ & 1 & $<0.001$ \\
\hline Positive, on ART $(n=201)$ & $33(16.4)$ & $0.54(0.39-0.73)$ & & $0.57(0.41-0.78)$ & \\
\hline Positive, not on ART $(n=396)$ & $133(33.6)$ & $1.62(1.34-1.96)$ & & $1.76(1.45-2.13)$ & \\
\hline \multicolumn{6}{|l|}{ BMI category } \\
\hline Underweight $(n=1701)$ & $459(27.0)$ & 1 & $<0.001$ & 1 & $<0.001$ \\
\hline Normal $(n=4878)$ & $1177(24.1)$ & $0.85(0.76-0.95)$ & & $0.98(0.87-1.10)$ & \\
\hline Overweight $(n=730)$ & $197(27.0)$ & $1.07(0.91-1.27)$ & & $1.29(1.07-1.55)$ & \\
\hline Obese $(n=198)$ & $74(37.4)$ & $1.70(1.29-2.24)$ & & $2.08(1.55-2.79)$ & \\
\hline \multicolumn{6}{|l|}{ Waist-hip ratio } \\
\hline Normal, $\leq 0.95-\mathrm{m}, \leq 0.80-\mathrm{f}(n=4440)$ & $1065(24.0)$ & 1 & 0.001 & 1 & $<0.001$ \\
\hline Abnormal, $>0.95-\mathrm{m},>0.80-\mathrm{f}(n=3067)$ & $842(27.5)$ & $1.17(1.07-1.28)$ & & $1.55(1.36-1.77)$ & \\
\hline \multicolumn{6}{|l|}{ Total cholesterol $(\mathrm{mmol} / \mathrm{L})$} \\
\hline Desirable $(\leq 5.2)(n=7084)$ & $1814(25.6)$ & 1 & 0.291 & 1 & 0.359 \\
\hline $\operatorname{High}(>5.2)(n=423)$ & $93(22.0)$ & $0.90(0.74-1.09)$ & & $0.91(0.74-1.12)$ & \\
\hline \multicolumn{6}{|l|}{$\mathrm{HbA1-C}$} \\
\hline Normal $\leq 6 \%(n=7469)$ & $1891(25.3)$ & 1 & 0.004 & 1 & 0.014 \\
\hline Raised $\geq 6.5 \%(n=19)$ & $11(57.9)$ & $3.65(1.49-8.93)$ & & $3.17(1.27-7.96)$ & \\
\hline
\end{tabular}

\footnotetext{
${ }^{\phi}$ High atherogenic risk versus intermediate and low risk.
} 


\section{Competing Interests}

The authors do not report any potential competing interests relevant to this paper.

\section{Authors' Contributions}

Anatoli Kamali conceived and designed the experiments. Clara Wekesa and Gershim Asiki performed the experiments. Ivan Kasamba, Laban Waswa, and Rebecca N. Nsubuga analysed the data. Clara Wekesa, Gershim Asiki, Rob Newton, and Steven J. Reynolds wrote the paper.

\section{Acknowledgments}

This work was supported and funded by the UK Medical Research Council (MRC) and the UK Department for International Development (DFID) under the MRC/DFID Concordat Agreement, University of Cambridge, UK, and the Wellcome Trust Sanger. Steven J. Reynolds was supported by the Division of Intramural Research, National Institute of Allergy and Infectious Diseases, National Institutes of Health. The authors would like to acknowledge the work of the GPC team and all other MRC/UVRI staff who contributed to this study. They are grateful to all the study participants. Support for paper writing was provided by Fogarty International Center, National Institutes of Health (Grant no. D43TW009771: "HIV Coinfections in Uganda: TB, Cryptococcus, and Viral Hepatitis").

\section{References}

[1] World Health Organisation, Cardiovascular Diseases (CVDs), World Health Organisation, Geneva, Switzerland, 2013.

[2] A. D. Alwan, G. Galea, and D. Stuckler, "Development at risk: addressing noncommunicable diseases at the United Nations high-level meeting," Bulletin of the World Health Organization, vol. 89, no. 8, pp. 546-546A, 2011.

[3] J. J. Dalal, T. N. Padmanabhan, P. Jain, S. Patil, H. Vasnawala, and A. Gulati, "Lipitension: Interplay between dyslipidemia and hypertension," Indian Journal of Endocrinology and Metabolism, vol. 16, no. 2, pp. 240-245, 2012.

[4] M. Twagirumukiza, D. de Bacquer, J. G. Kips, G. de Backer, R. V. Stichele, and L. M. Van Bortel, "Current and projected prevalence of arterial hypertension in sub-Saharan Africa by sex, age and habitat: an estimate from population studies," Journal of Hypertension, vol. 29, no. 7, pp. 1243-1252, 2011.

[5] P. Kotwani, D. Kwarisiima, T. D. Clark et al., "Epidemiology and awareness of hypertension in a rural Ugandan community: a cross-sectional study," BMC Public Health, vol. 13, article 1151, 2013.

[6] G. Musinguzi and F. Nuwaha, "Prevalence, awareness and control of hypertension in Uganda," PLoS ONE, vol. 8, no. 4, Article ID e62236, 2013.

[7] W. B. Kannel, "Fifty years of Framingham study contributions to understanding hypertension," Journal of Human Hypertension, vol. 14, no. 2, pp. 83-90, 2000.

[8] A. Bottger, H. A. Van Lith, V. Kren et al., "Quantitative trait loci influencing cholesterol and phospholipid phenotypes map to chromosomes that contain genes regulating blood pressure in the spontaneously hypertensive rat," Journal of Clinical Investigation, vol. 98, no. 3, pp. 856-862, 1996.

[9] F. Thomas, K. Bean, L. Guize, S. Quentzel, P. Argyriadis, and A. Benetos, "Combined effects of systolic blood pressure and serum cholesterol on cardiovascular mortality in young (< years) men and women," European Heart Journal, vol. 23, no. 7, pp. 528-535, 2002.

[10] P. Castelli and K. Anderson, "A population at risk: prevalence of high cholesterol levels in hypertensive patients in the Framingham study," The American Journal of Medicine, vol. 80, no. 2, pp. 33-39, 1986.

[11] P. W. F. Wilson, R. B. D’Agostino, D. Levy, A. M. Belanger, H. Silbershatz, and W. B. Kannel, "Prediction of coronary heart disease using risk factor categories," Circulation, vol. 97, pp. 1837-1847, 1998.

[12] M. R. Law, N. J. Wald, and S. G. Thompson, "By how much and how quickly does reduction in serum cholesterol concentration lower risk of ischaemic heart disease?" British Medical Journal, vol. 308, no. 6925, pp. 367-372, 1994.

[13] J. Millán, X. Pintó, A. Muñoz et al., "Lipoprotein ratios: physiological significance and clinical usefulness in cardiovascular prevention," Vascular Health and Risk Management, vol. 5, pp. 757-765, 2009.

[14] H. R. Superko and S. King, "Lipid management to reduce cardiovascular risk: a new strategy is required," Circulation, vol. 117, pp. 560-568, 2008.

[15] M. Dobiášová, "Atherogenic index of plasma [log(triglycerides/ HDL-cholesterol)]: theoretical and practical implications," Clinical Chemistry, vol. 50, no. 7, pp. 1113-1115, 2004.

[16] V. Bittner, B. D. Johnson, I. Zineh et al., "The triglyceride/highdensity lipoprotein cholesterol ratio predicts all-cause mortality in women with suspected myocardial ischemia. A Report From the Women's Ischemia Syndrome Evaluation (WISE)," American Heart Journal, vol. 157, no. 3, pp. 548-555, 2009.

[17] J. M. Gaziano, C. H. Hennekens, C. J. O’Donnell, J. L. Breslow, and J. E. Buring, "Fasting triglycerides, high-density lipoprotein, and risk of myocardial infarction," Circulation, vol. 96, no. 8, pp. 2520-2525, 1997.

[18] U. Nwagha, E. J. Ikekpeazu, F. E. Ejezie, E. E. Neboh, and I. C. Maduka, "Atherogenic index of plasma as useful predictor of cardiovascular risk among postmenopausal women in Enugu, Nigeria," African Health Sciences, vol. 10, no. 3, pp. 248-252, 2010.

[19] K. Wan, J. Zhao, H. Huang et al., "The association between triglyceride/high-density lipoprotein cholesterol ratio and allcause mortality in acute coronary syndrome after coronary revascularization," PLoS ONE, vol. 10, no. 4, Article ID e0123521, 2015.

[20] W. P. Castelli, "Epidemiology of coronary heart disease: The Framingham Study," The American Journal of Medicine, vol. 76, no. 2, pp. 4-12, 1984.

[21] M. Dobiášová, "AIP—atherogenic index of plasma as a significant predictor of cardiovascular risk: from research to practice," Vnitrni Lekarstvi, vol. 52, no. 1, pp. 64-71, 2006.

[22] D. Guwatudde, G. Mutungi, R. Wesonga et al., "The epidemiology of hypertension in Uganda: findings from the national noncommunicable diseases risk factor survey," PLoS ONE, vol. 10, no. 9, Article ID e0138991, 2015.

[23] G. Asiki, G. A. V. Murphy, K. Baisley et al., "Prevalence of dyslipidaemia and associated risk factors in a rural population in South-Western Uganda: a community based survey," PLoS ONE, vol. 10, no. 5, Article ID e0126166, 2015. 
[24] G. F. Watts, "Treating patients with low HDL-cholesterol: choices, issues and opportunities," Current Controlled Trials in Cardiovascular Medicine, vol. 2, no. 3, pp. 118-122, 2001.

[25] G. Asiki, G. Murphy, J. Nakiyingi-Miiro et al., "The general population cohort in rural south-western Uganda: a platform for communicable and non-communicable disease studies," International Journal of Epidemiology, vol. 42, no. 1, pp. 129-141, 2013.

[26] J. Riha, A. Karabarinde, G. Ssenyomo et al., "Urbanicity and lifestyle risk factors for cardiometabolic diseases in rural Uganda: a cross-sectional study," PLoS Medicine, vol. 11, no. 7, Article ID e1001683, 2014.

[27] WHO, Use of Glycated Haemoglobin (HbA1c) in the Diagnosis of Diabetes Mellitus, World Health Organization, 2011.

[28] Uganda National Policy Guidelines for HIV Counselling and Testing Ministry of Health Uganda, 2003.

[29] National Guidelines for Research Involving Humans as Research Participants, UNCST, Kampala, Uganda, 2007.

[30] J. Idemudia, E. Ugwuja, O. Afonja, E. Idogun, and N. Ugwu, "CReactive proteins and cardiovascular risk indices in hypertensive Nigerians," The Internet Journal of Cardiovascular Research, vol. 6 , no. 2, 2008.

[31] S. Niroumand, M. Khajedaluee, M. Khadem-Rezaiyan et al., "Atherogenic Index of Plasma (AIP): a marker of cardiovascular disease," Medical Journal of The Islamic Republic of Iran (MJIRI), vol. 29, p. 240, 2015.

[32] S. Yusuf, S. Hawken, S. Ônpuu et al., "Effect of potentially modifiable risk factors associated with myocardial infarction in 52 countries (the INTERHEART study): case-control study," The Lancet, vol. 364, no. 9438, pp. 937-952, 2004.

[33] P. L. Da Luz, D. Favarato, J. R. Faria-Neto Jr., P. Lemos, and A. C. P. Chagas, "High ratio of triglycerides to HDL-cholesterol predicts extensive coronary disease," Clinics, vol. 63, no. 4, pp. 427-432, 2008.

[34] D. Périard, A. Telenti, P. Sudre et al., "Atherogenic dyslipidemia in HIV-infected individuals treated with protease inhibitors," Circulation, vol. 100, no. 7, pp. 700-705, 1999.

[35] V. A. Triant, "HIV infection and coronary heart disease: an intersection of epidemics," Journal of Infectious Diseases, vol. 205, no. 3, pp. S355-S361, 2012.

[36] C. J. O’Donnell and R. Elosua, "Cardiovascular risk factors. Insights from framingham heart study," Revista Española de Cardiología, vol. 61, no. 3, pp. 299-310, 2008. 


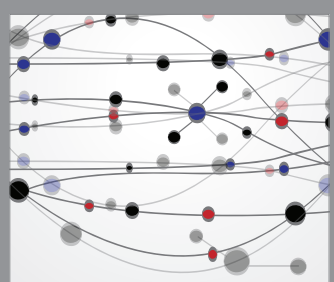

The Scientific World Journal
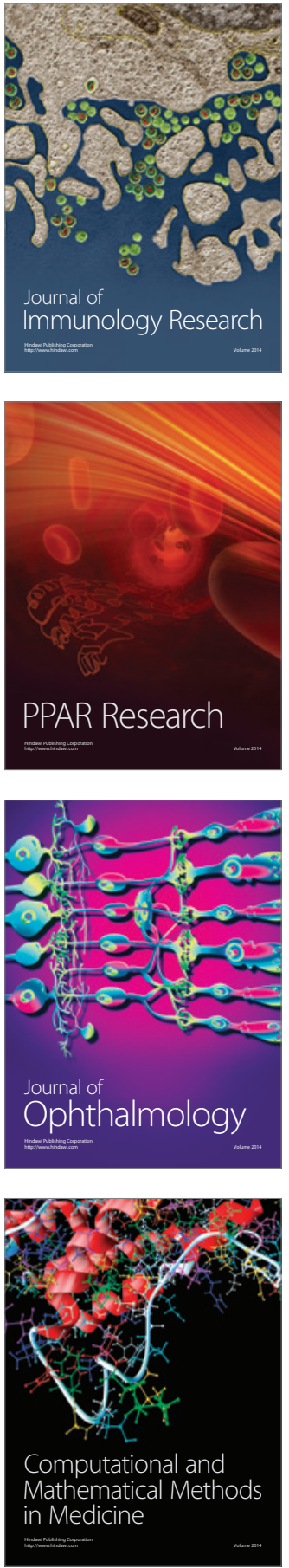

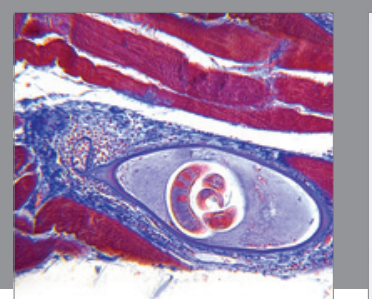

Gastroenterology Research and Practice

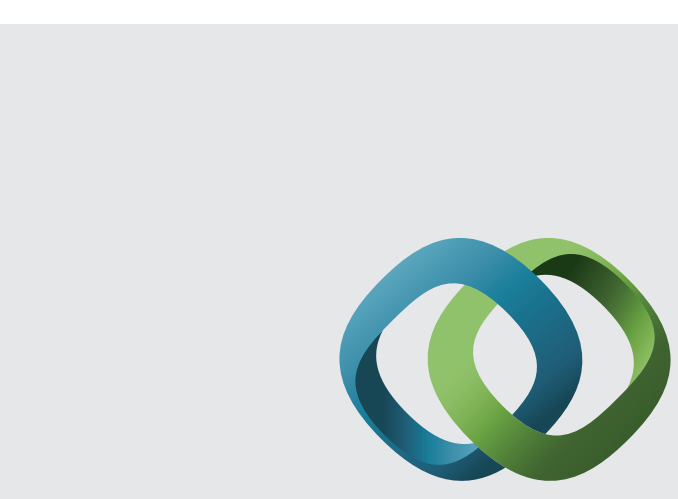

\section{Hindawi}

Submit your manuscripts at

http://www.hindawi.com
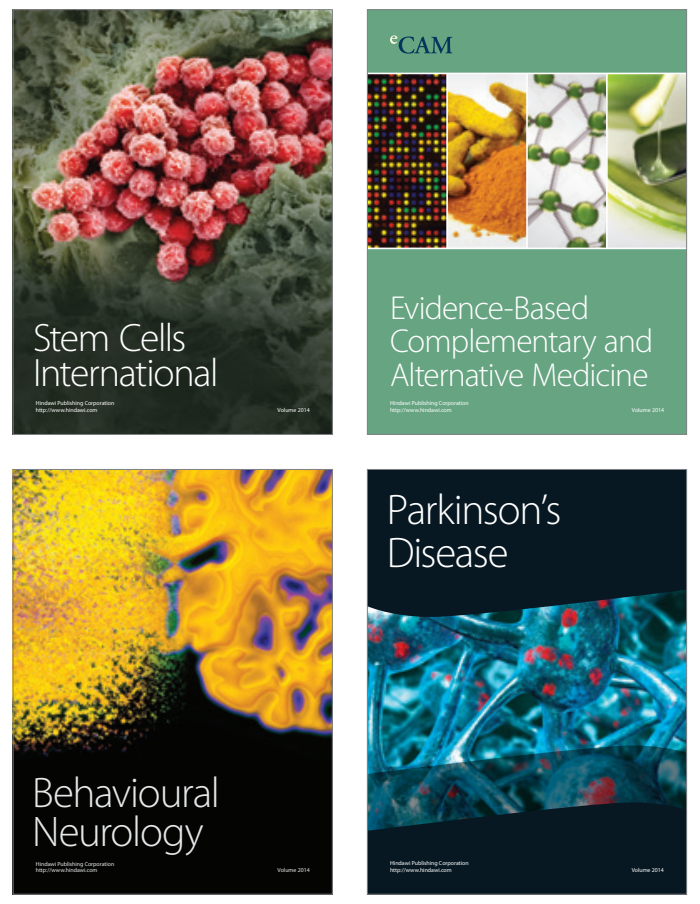
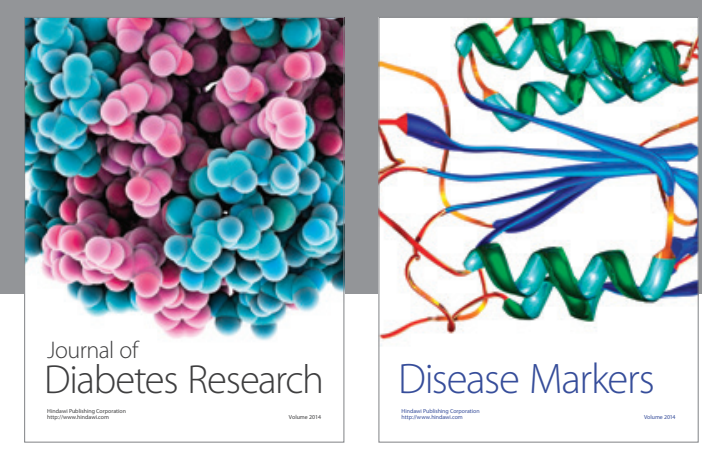

Disease Markers
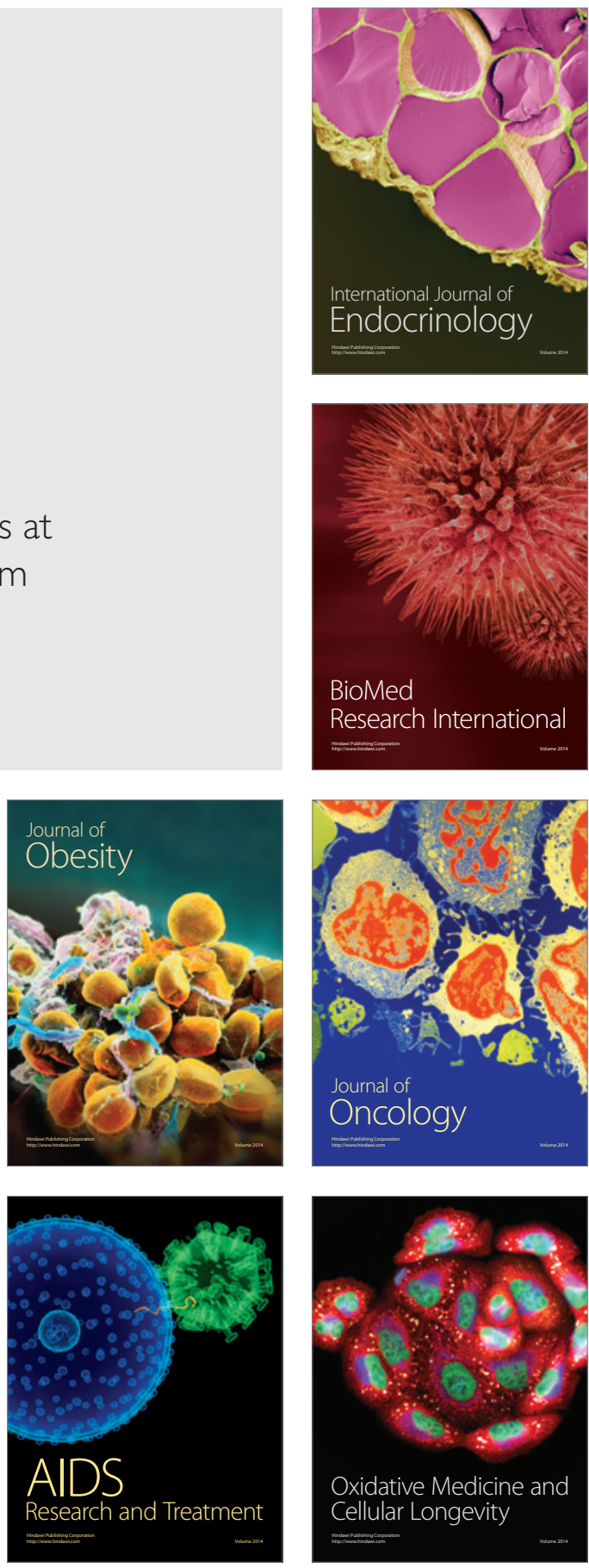